\section{Dental practitioners and ill health retirement: causes, outcomes and re-employment}

\author{
J. Brown, ${ }^{1}$ F. J. T. Burke, ${ }_{1}^{2}$ E. B. Macdonald ${ }^{3}$ H. Gilmour, ${ }^{4}$ K. B. Hill, ${ }_{1}^{5}$ \\ A. J. Morris, ${ }^{6}$ D. A. White, ${ }^{7}$ E. K. Muirhead ${ }^{8}$ and K. Murray ${ }^{9}$
}

\section{IN BRIEF}

- The most common cause of IHR was musculoskeletal disorders. A majority of respondents considered that their ill health was work related.

- The majority were able to work up to their retirement and a similar number would have liked to continue working.

- It is likely that many of the ill health retirees could have been retained in the dental workforce with better support or opportunities for more flexible working.

\begin{abstract}
Aim The aim of this project was, by means of a questionnaire to ill health retirees, to determine the factors which have contributed to the premature retirement of general dental practitioners (GDPs) due to ill health. Methods A questionnaire was designed to determine the effects of illness and ill health retirement (IHR) on the lives of those dentists who were affected. This was distributed to 207 dentists who were known to have retired because of ill health but were not suffering from serious, debilitating or life-threatening illnesses. Results A total of 189 questionnaires were returned. The mean age at retirement of respondents was 51.5 years, with a range of 31 to 62 years. Of the respondents, $90 \%$ selected general dental practitioner as their last job title. The most common cause of IHR was musculoskeletal disorders (55\%), followed by mental and behavioural disorders (28\%). A majority of respondents (90\%) considered that their ill health was work related. Sixty-three percent of respondents stated that they were able to keep working until their retirement, 34\% of respondents stated that they would have liked to have been offered part-time work as an alternative to full retirement, and 27\% of dentists reported to have found re-employment since their retirement. In univariate analyses, re-employment of dentists after IHR was significantly associated with age, having dependants, cause of IHR, health having improved and wanting to work again. Multiple logistic regression analyses showed that a combination of age, having dependents and cause of IHR was predictive of re-employment status $(p=0.024)$. Conclusion This study used a database of dentists who were ill health retired and who were not suffering from life threatening illnesses The results confirmed that the majority were able to work up to their retirement and a similar number would have liked to continue working, particularly if part-time work had been possible. It seems likely that many of the ill health retirees could have been retained in the dental workforce with better support or opportunities for more flexible working.
\end{abstract}

\section{INTRODUCTION}

Data published in 1999 from the Government Actuary on the National Health Service Pension Scheme (1989-1994) have indicated that the frequency of premature ill health retirement (IHR) was four times more prevalent among dentists at age 42 years compared with medical doctors, ${ }^{1}$

\footnotetext{
${ }^{1}$ Research Fellow, Healthy Working Lives Group, ${ }^{3}$ Head of Healthy Working Lives Group/Honorary Professor, ${ }^{9}$ Research Fellow, Healthy Working Lives Group, 4 Senior Lecturer in Medical Statistics, Public Health and Health Policy Section, Division of Community Based Sciences, 1 Lilybank Gardens, University of Glasgow, Glasgow, G12 8RZ; 2* Professor of Primary Dental Care, ${ }^{5}$ Lecturer in Dental Public Health and Behavioural Science, ${ }^{6}$ Senior Lecturer, ${ }^{7}$ Associate Professor of Dental Public Health, ${ }^{8}$ Research Assistant, Primary Dental Care Research Group, University of Birmingham School of Dentistry, St.Chad's Queensway, Birmingham, B4 6NN ${ }^{*}$ Correspondence to: Professor Trevor Burke

Email:f.j.t.burke@bham.ac.uk;

Tel: +44 (0)121237 2767
}

\section{Online article number E7}

Refereed Paper - Accepted 19 February 2010

DOI: $10.1038 /$ sj.bdj.2010.813

British Dental Journal 2010; 209: E7 who might be considered an equivalent group in terms of qualifications and training. It may be considered that examination of reasons for premature retirement would provide information on diseases which incapacitate dentists, but contemporary comprehensive data regarding the reasons for premature retirement due to illness among dentists has proved difficult to obtain. Data presented by Burke and coworkers in April 1997, representing only a small proportion of the dental population, identified reasons for premature retirement of dental practitioners on health grounds, with musculoskeletal disorders and stressrelated illnesses being the most frequently cited groups of conditions. ${ }^{2}$ In this respect, statistics collected almost two decades ago suggested that dentistry was the most stressful of healthcare professions. ${ }^{3}$ Cooper and co-workers, in 1987, suggested that dentists face a set of unique problems such as time-related pressures, fearful patients, financial worries and staff problems, along with the repetitive nature of the job. ${ }^{4}$ They also found that dentists had significantly lower mental well-being than a comparable group from the general population. ${ }^{4}$ On the other hand, a US study published in 1976 indicated that dentists' mortality rates were lower than other professional groups for the most common causes of death, with $73 \%$ of deaths occurring after the age of $64 .{ }^{5}$ In the UK, dentists have the lowest mortality rates for all cancers, heart disease, cerebrovascular disease and chronic lung disease among healthcare professionals. ${ }^{6}$ Nevertheless, the results of an evaluation of UK general dental practitioner stress levels indicated that one in three of the respondents were considerably dissatisfied with their job. ${ }^{3}$ Negative patient perceptions and scheduling problems were noted as the primary factors relating to poor job satisfaction. More recently, Gilmour and colleagues assessed the level 
of job satisfaction among 297 general dental practitioners in Staffordshire, England, with the results indicating that $57 \%$ were satisfied with their career in dentistry but that job-related stress was associated with the greatest proportion of dissatisfaction.?

Regarding stress and burnout in general dental practitioners, sources of stress have been identified by Blinkhorn as being the payment system, a feeling of being undervalued and the feeling of being trapped in a practice until retirement, ${ }^{8}$ while Osborne and Croucher, when assessing burnout among dental practitioners in South East England, concluded that general dental practice had characteristics which were likely to produce high levels of jobrelated stress, and with $11 \%$ of practitioners exhibiting high overall burnout levels. ${ }^{9}$ In general it would be expected that the incidence of disease among dentists would be lower compared with that from other groups within the population since dentists belong to a higher socio-economic grouping. ${ }^{10,11}$ In a study of gender-related differences in burnout among Dutch dentists, Te Brake and co-workers found no gender differences in work stress or health-related aspects but that male dentists worked longer hours than female dentists. ${ }^{12}$ Scully and co-workers ${ }^{11}$ compared standardised mortality ratios (SMRs) among dentists and demonstrated that dentists had lower SMRs than the general population in the UK and USA, with 73\% of dentists living beyond the age of retirement. It would therefore appear that dentists are not, in general, at increased risk from illnesses, but, nevertheless, a proportion of these physical and mental illnesses result in IHR.

A small number of studies have examined the impact of musculoskeletal problems among dentists. Shugars and colleagues reported the results of a 1985 survey of 2,000 US dentists. Sixty percent of respondents reported that they had experienced some type of musculoskeletal pain during the previous year. Of those who reported musculoskeletal pain, the location of the pain with the highest incidence was lower back (37\% of respondents), followed by neck (17\%). ${ }^{13}$ In addition, respondents who reported having pain stated that pain was present from 65 to 125 days per year and almost a third of those who experienced pain indicated that physical and leisure activities were interrupted because of pain. Pain was found to cause the cancellation of one day of practice per year, extrapolated by the authors to mean 1.3 million cancelled patient appointments per annum. ${ }^{13}$ More recently, Finsen and co-workers investigated musculoskeletal disorders among 115 dentists in Denmark who were members of the Danish Society for Craniomandibular Disorders. Two thirds of the respondents reported pain or discomfort in the neck and/or shoulder region in the year preceding the survey, with a similar figure being reported for low back pain. Older dentists were found to have fewer reported neck problems than younger dentists, but hours worked had a significant impact, with dentists who worked longer hours reporting more neck problems. ${ }^{14}$

Lastly, Lake, in a review of the literature on musculoskeletal problems associated with the practice of dentistry, concluded that musculoskeletal dysfunctions such as tendonitis, muscular strains, carpal tunnel syndrome, Raynaud's phenomenon and cervical arthroses are associated with the practice of dentistry. ${ }^{15}$ She advised that the dentist must take responsibility for their own physical wellbeing, monitoring symptoms and taking advice early.

Despite these studies, there is a paucity of information on the predisposing factors which initiate a dentist's decision to retire on health grounds, since this was not their focus. In addition, little is known about the alternative career choices made to dentists concerning IHR, such as employment outside of clinical dentistry or reduced hours of work. Accordingly, in view of the information contained in the Government Actuary's report ${ }^{1}$ and the shortage of dentists identified by the Primary Care Dental Workforce Review published in 2004, ${ }^{16}$ it was considered appropriate to investigate these factors.

The aim of this project was to determine the factors which have contributed to the premature retirement of general dental practitioners (GDPs) due to ill health. The objectives were to obtain a sample of dentists who had retired through IHR and use a questionnaire to determine:

- The effect of premature retirement upon their life

- Any potential remediable factors which might have led to their remaining in the workplace, and
- Assess rehabilitation needs which may not have not been met.

Specific research questions included:

1. What factors are associated with, and possibly predispose, to premature retirement on health grounds from dental practice?

2. What is the effect of IHR upon the health and quality of life of those who retire?

3. What potential remedial factors might prevent or forstall premature retirement?

4. Was any rehabilitation offered to the ill health retirees which would have enabled them to continue in work?

5. What are the predictors of returning to work after IHR?

\section{METHODS}

\section{The questionnaire}

A questionnaire was designed to determine the effects of illness and ill health retirement (IHR) on the lives of those dentists who were affected. It was derived from one used successfully by Macdonald and co-workers in recent research into Scottish teachers' and healthcare workers' premature retirement due to ill health. ${ }^{17-19}$ In addition, the questionnaire also addressed work ability of the participants. In this respect, the concept of work ability can be defined as the ability of a worker to perform his/her job, taking into account the specific work demands and mental resources. ${ }^{20}$

The questionnaire also included the questions from the HADS (Hospital Anxiety and Depression Scale) questionnaire, ${ }^{21}$ a validated questionnaire consisting of 14 items and yielding two measures, one for anxiety and one for depression. Scores on both scales can range between 0 and 21. A higher score indicates a more severe condition. A score of 7 or less is considered 'normal', a score between 8 and 10 'mild', a score between 11 and 15 'moderate', and a score greater or equal to 16 'severe'. Moderate and severe scores indicate "caseness', that is individuals who would be considered anxious or depressed. A largescale $(n=1,792)$ normative study carried out on a non-clinical sample of the UK population found an average score of 6.14 for anxiety and 3.68 for depression. ${ }^{21}$ 
The questionnaire was piloted with ten dentists who had retired prematurely due to ill health. A number of changes, including deletion of several sections, were made following feedback from these dentists. The final questionnaire contained a total of 77 questions, 13 of which included subsections requesting additional information.

\section{The subjects}

Previous correspondence with a dental sickness insurance company indicated that a proportion of their members who had retired prematurely on health grounds would be prepared to co-operate in this research. Accordingly, following contact with a company specialising in health insurance for dentists (Wesleyan Medical Sickness: WMS), it was agreed that they would send a letter to their members who had retired prematurely due to ill health, since, because of the need to protect confidentiality, it was not appropriate for the researchers to contact the retirees directly. The letter requested the co-operation of the retired dentist in responding to the questionnaire; it also stated that that WMS would have no further involvement in the project.

Analysis of the WMS database of retirees who were known to have retired through ill health indicated that 207 (of 594) members were suffering from serious, debilitating or life-threatening illnesses as defined by the insurance arrangements. It was decided jointly between WMS and the research team that it would be inappropriate to ask these dentists to respond to a questionnaire. Accordingly, the letter from WMS requesting help was distributed, in September 2006, to 387 retired dentists. Of these, 210 replied positively and provided their names and addresses. The questionnaire was sent by post to these dentists, with a reply-paid envelope and a covering letter explaining the aims of the project. The letter requesting participation in the research explained that this would be carried out by way of completion of a detailed questionnaire designed to examine the dentist's life history and job satisfaction, issues involved in the decision to retire, whether alternatives to retirement were offered, and changes in quality of life since retirement. The dentists were informed that they would be reimbursed for the time taken completing the questionnaire. They were also asked if they would be prepared to take part in a telephone interview. The data from the completed questionnaires were collated and analysed.

\section{Data analysis}

Analysis of the completed questionnaires was undertaken on SPSS version 15.0. We investigated the likelihood of taking up employment after IHR in relation to seven factors recorded in the questionnaire. The possible predictors were sex, age, dependants, managerial responsibility, cause of IHR, health improvement and wanting to work again. Age was recoded into three categories (less than 50, 50-54 and 55+). Cause of IHR was recoded as either mental disorder or all other diseases. The relative chance of re-employment was initially estimated by odds ratios (ORs) calculated for each predictive variable separately. Multiple logistic regression models excluding 'health improvement' and 'wanting to work again' provided adjusted OR and their confidence intervals.

\section{Telephone interviews}

A sample of 29 respondents was selected from those subjects who agreed, in their replies to the questionnaire, to either a telephone interview or a face-to-face interview with a researcher who was trained in interview techniques. The findings from these interviews are presented in a separate paper.

\section{RESULTS}

A total of 189 questionnaires were returned, 28 from female dentists and 161 from male dentists. This represents a $90 \%$ response rate from the dentists who agreed to participate in the project, but a $50 \%$ response rate from those retirees who were originally contacted by WMS.

\section{Demographic details}

The mean age at retirement of respondents was 51.5 years, with a range of 31 to 62 years. Of the respondents, 90\% ( $n=170$ ) selected general dental practitioner as their last 'job title', with 108 of these being mainly National Health Service (NHS) and the others being mixed NHS/ private or wholly private. Of the general dental practitioners, 70\% reported being practice owners.

Data on IHR are as follows:

- Regarding the number of years for
Table 1 Reported cause of IHR in dentists who retired with non-life-threatening illnesses

\begin{tabular}{l|l}
\hline Cause & Number (\%) \\
\hline Musculoskeletal & $104(55 \%)$ \\
\hline Mental and behavioural disorders & $54(28 \%)$ \\
\hline Nervous system/sense organs & $17(9 \%)$ \\
\hline Circulatory & $4(2 \%)$ \\
\hline Neoplasms & $3(2 \%)$ \\
\hline Other & $7(4 \%)$ \\
\hline
\end{tabular}

which respondents worked as a dentist, the mean was 27.4 years, with the shortest time being 5 years and the longest being 39 years

- Seventy-seven percent $(n=146)$ of respondents reported that they worked full-time at the time of their retirement and $76 \%(n=142)$ reported that their job involved supervisory or managerial responsibility

- Sixty-three percent $(n=116)$ of respondents stated that they were able to keep working until their retirement, and, of those who were off work before retirement, this was for a mean time of 10.9 months

- When asked if they felt that their ill health was work related, 10\% ( $\mathrm{n}=19)$ replied that it was not work related, while $42 \%(n=80)$ replied that their retirement was 'partly work related' and 48\% ( $\mathrm{n}=90)$ 'completely work related'

- Ninety-five percent of respondents ( $n=179$ ) stated that they had consulted their general practitioner because of the illness that led to their retirement.

\section{Causes of IHR}

It should be noted that this study addresses IHR in dentists who retired with non lifethreatening illnesses and Table 1 illustrates the causes of IHR of these respondents.

The most common cause of IHR was musculoskeletal disorders, followed by mental and behavioural disorders and disease of the nervous system/sense organs. 'Other' included diseases of the respiratory system, digestive system, endocrine and skin.

Interestingly, results from the HADS part of the questionnaire indicated that, while $28 \%$ of dentists retired early because of 
mental health problems, the data from the completed HADS questions indicated that only 20\% were anxious and 10\% depressed on completion of the questionnaire.

\section{Support}

Regarding support before retirement, 37\% of respondents $(n=69)$ reported contacting a support organisation (the British Dental Association being an example), with $71 \%(n=49)$ finding that this was helpful. Ninety-five percent of respondents $(n=176)$ considered that their general medical practitioner was supportive, 94\% ( $\mathrm{n}=178$ ) had been referred to a consultant, with 95\% ( $\mathrm{n}=174$ ) of these being considered supportive.

\section{Occupational health advice}

Twenty-eight percent of respondents ( $n=52$ ) stated that they were offered occupational health advice before their IHR, with $71 \%(n=40)$ reporting this to be useful. This advice was obtained from a wide variety of sources, including consultants, advisers and physicians in occupational health, general medical practitioners and physiotherapists. of those respondents who reported not receiving occupational health advice, 92\% ( $n=140$ ) stated that they would have liked to have been offered such advice.

Most frequently quoted suggestions for the advice that should be given included:

- Advice on posture and better working practices

- Coping with (workplace) stress

- Coping with the stress of being ill and managing recovery

- Future career possibilities and retraining.

One respondent suggested that everyone should be allowed a sabbatical after being in practice for a few years, as this might improve long-term retention.

\section{Alternative working patterns}

When asked whether they were offered the option of working part-time in the period preceding ill health retirement, 13\% ( $\mathrm{n}=24$ ) reported such an offer, although $28 \%(n=52)$ replied that they were already working part-time. Of those who reported an offer of part-time work, $70 \%(\mathrm{n}=21)$ took up this option. Thirty-four percent of respondents $(n=44)$ stated that they would have liked to have been offered part-time

\begin{tabular}{|c|c|c|c|c|}
\hline Variable & $\begin{array}{l}\text { No. } \\
\text { retired }\end{array}$ & $\begin{array}{l}\text { No. back to } \\
\text { work }(\%)\end{array}$ & $\begin{array}{l}\text { Unadjusted OR } \\
(95 \% \mathrm{Cl})^{\mathrm{a}}\end{array}$ & $\begin{array}{l}\text { Adjusted OR (95\% } \\
\mathrm{CI})^{\mathrm{b}, \mathrm{c}}\end{array}$ \\
\hline $\begin{array}{l}\text { Sex } \\
\text { Male } \\
\text { Female }\end{array}$ & $\begin{array}{l}161 \\
27\end{array}$ & $\begin{array}{l}41(25) \\
10(37)\end{array}$ & $\begin{array}{l}p=0.211 \\
1.00 \\
1.72(0.73,4.06)\end{array}$ & \\
\hline $\begin{array}{l}\text { Age-group } \\
\begin{array}{l}55+ \\
50-54 \\
<50\end{array}\end{array}$ & $\begin{array}{l}65 \\
62 \\
59\end{array}$ & $\begin{array}{l}13(20) \\
14(23) \\
23(39)\end{array}$ & $\begin{array}{l}p=0.038 \\
1.00 \\
1.17(0.50,2.73) \\
2.56(1.15,5.70)\end{array}$ & $\begin{array}{l}p=0.158 \\
1.00 \\
0.96(0.40,2.31) \\
1.94(0.83,4.51)\end{array}$ \\
\hline $\begin{array}{l}\text { Dependants } \\
\text { No } \\
\text { Yes }\end{array}$ & $\begin{array}{l}96 \\
92\end{array}$ & $\begin{array}{l}20(21) \\
31(34)\end{array}$ & $\begin{array}{l}p=0.047 \\
1.00 \\
1.93(1.00,3.72)\end{array}$ & $\begin{array}{l}p=0.072 \\
1.00 \\
1.88(0.95,3.73)\end{array}$ \\
\hline $\begin{array}{l}\text { Managerial responsibility } \\
\text { No } \\
\text { Yes }\end{array}$ & $\begin{array}{l}45 \\
142\end{array}$ & $\begin{array}{l}10(22) \\
41(29)\end{array}$ & $\begin{array}{l}p=0.383 \\
1.00 \\
1.42(0.64,3.13)\end{array}$ & \\
\hline $\begin{array}{l}\text { Cause of IHR } \\
\text { All other diseases } \\
\text { Mental disorder }\end{array}$ & $\begin{array}{l}135 \\
54\end{array}$ & $\begin{array}{l}31(23) \\
20(37)\end{array}$ & $\begin{array}{l}p=0.049 \\
1.00 \\
1.97(1.00,3.91)\end{array}$ & $\begin{array}{l}p=0.129 \\
1.00 \\
1.77(0.85,3.67)\end{array}$ \\
\hline $\begin{array}{l}\text { Health improved } \\
\text { No } \\
\text { Yes }\end{array}$ & $\begin{array}{l}82 \\
107\end{array}$ & $\begin{array}{l}16(20) \\
35(33)\end{array}$ & $\begin{array}{l}p=0.043 \\
1.00 \\
2.01(1.02,3.96)\end{array}$ & \\
\hline $\begin{array}{l}\text { Want to work again } \\
\text { No } \\
\text { Yes }\end{array}$ & $\begin{array}{l}108 \\
37\end{array}$ & $\begin{array}{l}18(17) \\
22(59)\end{array}$ & $\begin{array}{l}p<0.001 \\
1.00 \\
7.33(3.20,16.80)\end{array}$ & \\
\hline \multicolumn{5}{|c|}{$\begin{array}{l}\text { Unadjusted odds ratio (relative chance of finding re-employment after IHR) obtained from cross-tabulations } \\
\text { 'Adjusted odds ratio obtained from a multiple logistic regression model } \\
\text { 'The overall multiple logistic regression model including age, dependents and cause of IHR was predictive of re-employment } \\
\text { tatus ( } p=0.024 \text { ) }\end{array}$} \\
\hline
\end{tabular}

Table 3 All probabilities of subsequent employment after IHR from logistic regression model

\begin{tabular}{l|l|l|l|l|l|l}
\hline \multirow{2}{*}{} & \multicolumn{2}{|c|}{$<50$} & \multicolumn{2}{c|}{$50-54$} & \multicolumn{2}{c}{$55+$} \\
\cline { 2 - 6 } & Dependants & $\begin{array}{l}\text { No } \\
\text { dependants }\end{array}$ & Dependants & $\begin{array}{l}\text { No } \\
\text { dependants }\end{array}$ & Dependants & $\begin{array}{l}\text { No } \\
\text { dependants }\end{array}$ \\
\hline $\begin{array}{l}\text { Mental } \\
\text { Health as } \\
\text { cause of } \\
\text { IHR }\end{array}$ & $53.5 \%$ & $38.0 \%$ & $36.3 \%$ & $23.3 \%$ & $37.2 \%$ & $24.0 \%$ \\
\hline $\begin{array}{l}\text { Cause of } \\
\text { IHR not } \\
\text { mental } \\
\text { health }\end{array}$ & $39.4 \%$ & $25.7 \%$ & $24.4 \%$ & $14.7 \%$ & $25.1 \%$ & $15.2 \%$ \\
\hline
\end{tabular}

work. Twenty-eight percent of respondents $(n=52)$ replied that they investigated alternative work before retirement, and of those who did not, 45\% ( $=63$ ) replied that they would have liked help in investigating alternative employment.

\section{Effect of retirement}

When asked 'At the point of retirement did you feel under strain?'

- Six percent $(n=11)$ of respondents stated 'not at all'

- Eleven percent $(n=21)$ stated 'no more than usual'

- Sixteen percent $(n=31)$ stated 'rather more than usual'
- Sixty-seven percent $(n=126)$ stated 'much more than usual'.

Following IHR:

- Fifteen percent $(n=29)$ of respondents stated that they were less happy than usual

- Twenty-nine percent ( $\mathrm{n}=54$ ) responded that they were as happy as usual

- Fifty-six percent $(n=106)$ considered that they were more happy than usual.

Forty-three percent of respondents ( $n=81$ ) stated that they felt a loss of status since IHR and this was considered to cause 
stress to $35 \%(n=29)$ of these. Fifty-four percent of respondents $(n=102)$ reported that they enjoyed things that they used to enjoy more than they could before IHR and half reported that they laughed more after they retired.

\section{Current health and re-employment status}

Regarding health post-retirement, 57\% ( $\mathrm{n}=107$ ) of respondents reported that their health had improved since retirement. Twenty-seven percent of respondents $(n=51)$ stated that they would like to work again, with 27\% ( $\mathrm{n}=51)$ reporting that they had obtained other work since IHR, with a majority of this work being reported as being voluntary. Twenty-three percent $(n=44)$ of respondents chose not to answer this question.

\section{Predictors of re-employment}

On univariate (unadjusted) analyses, reemployment of dentists after IHR was significantly associated with age, having dependants, cause of IHR, health having improved and wanting to work again. No significant association was found with gender or having managerial responsibility (Table 2).

Although health having improved and wanting to work again were included as possible predictors of returning to work, they would not be particularly useful at the decision point of IHR and therefore were not included in subsequent analyses. Multiple logistic regression analyses showed that, in the final model, none of the three variables individually were significant after adjusting for the others, but the combination of these three variables is predictive of re-employment status ( $p=0.0 .24$ ) (Table 2).

Table 3 shows four examples of probabilities of returning to work after IHR based on the fitted logistic regression model. The estimated probability of a dentist aged $<50$ years, having dependants and retiring with a mental health problem obtaining work after IHR was 54\%. The estimated probability of a dentist aged $55+$ returning to work, having dependants and who retired with a mental health problem, was 37\%. A dentist aged 50-54, having dependants and retiring because of a mental health problem has an estimated probability of returning to work of 36\%.
The estimated probability of a dentist aged $55+$ returning to work, with no dependants and who retired with an illness other than a mental health problem, was 15\%.

\section{Views on career and employment}

The respondents' feeling about their career before IHR is presented in Table 4, with a majority (63\%) presenting positive feelings about their career. However, when asked about their feelings on their past method of employment, only $43 \%$ were positive (Table 5).

\section{Income protection}

Ninety-four percent of respondents ( $n=177$ ) reported that they had income protection before retirement and 70\% ( $n=131$ ) made a claim on this. Of these, $97 \%(n=127)$ reported that the claim was successful. Regarding the attitude of the NHS Pensions Agency, 81\% of respondents reported that they were helpful, while the attitude of private insurance companies was considered helpful by $69 \%$ of respondents.

\section{Self-help groups}

Thirty-eight percent of respondents ( $n=71$ ) considered that a self-help group would have been advantageous.

\section{Health and well-being}

When asked to rate their present health, respondents answered as shown in Table 6. Of the respondents, 52\% considered that they were 'limited a lot' in doing vigorous activities, 24\% $(n=45)$ were 'limited a little' and 25\% ( $=46)$ not 'limited at all'. On a similar theme, $18 \%$ of respondents ( $n=33$ ) were 'completely satisfied'

\begin{tabular}{|l|l|l|}
\hline \multicolumn{3}{|c|}{ Table 4 Feelings about work before IHR } \\
\hline Feeling & $\begin{array}{l}\% \\
\text { respondents }\end{array}$ & $\begin{array}{l}\text { Number of } \\
\text { respondents }\end{array}$ \\
\hline Very positive & 30 & 58 \\
\hline Positive & 33 & 62 \\
\hline Neutral & 13 & 24 \\
\hline Negative & 12 & 23 \\
\hline Very negative & 12 & 23 \\
\hline
\end{tabular}

Table 5 Respondents' feelings about their past method of employment

\begin{tabular}{l|l|l} 
Feeling & $\begin{array}{l}\% \\
\text { respondents }\end{array}$ & $\begin{array}{l}\text { Number of } \\
\text { respondents }\end{array}$ \\
\hline Very positive & 18 & 33 \\
\hline Positive & 25 & 46 \\
\hline Neutral & 23 & 44 \\
\hline Negative & 20 & 38 \\
\hline Very negative & 14 & 27
\end{tabular}

with their physical ability to do what they wanted to do, 16\% ( $\mathrm{n}=31$ ) being 'very satisfied', 28\% ( $n=52$ ) being 'somewhat satisfied', 29\% ( $\mathrm{n}=54)$ being 'somewhat dissatisfied', and 9\% ( $\mathrm{n}=17$ ) being 'very' or 'completely dissatisfied'. A small proportion of respondents (16\%: $n=29)$ stated that they needed help with mobility and a further 7\% were confined to a bed or a chair for most or all of the day because of their health.

\section{HADS scores}

The mean anxiety score was 6.39 and the mean depressive score was 4.37 (very near the normative study referenced earlier). Table 7 shows the percentage of

\begin{tabular}{l} 
Table 6 Respondents' assessments of their present health \\
\hline Good
\end{tabular}

Table 7 Results from HADS questionnaire

\begin{tabular}{l|l|l}
\hline & Table 7 Results from HADS questionnaire \\
\hline & Anxiety score & Depression score \\
\hline Normal & $60 \%$ & $80 \%$ \\
\hline Mild & $20 \%$ & $10 \%$ \\
\hline Moderate & $16 \%$ & $8 \%$ \\
\hline Severe & $4 \%$ & $2 \%$
\end{tabular}


respondents scoring normal, mild, moderate or severe scores. Moderate and severe scores indicate 'caseness'. In this study $20 \%$ of respondents were anxious and 10\% were depressed.

\section{DISCUSSION}

Internationally, research has demonstrated that dentistry may be a stressful occupation, with studies from as far afield as Denmark, ${ }^{22}$ the United States, ${ }^{23}$ Israel, ${ }^{24}$ the United Kingdom ${ }^{2-4,8,9}$ and Southern Thailand ${ }^{25}$ confirming this. A lack of career perspective has been found to be a stress factor most related to burnout in a survey of Dutch dentists. ${ }^{26}$ However, the evidence is by no means equivocal ${ }^{5,6,11}$ and a reasonable proportion of a group of UK dentists appear to be satisfied with their careers. ${ }^{7}$

Results of research into musculoskeletal disorders, again covering much of the world, has shown a prevalence of musculoskeletal problems among dentists, with research among dentists in Sweden indicating that female dental health workers are at special risk of development of musculoskeletal disorders of the upper extremities, ${ }^{27}$ that dentists in Poland worked in conditions which produced disorders of the musculoskeletal system, ${ }^{28}$ and that musculoskeletal problems are a common source of premature retirement in the US ${ }^{29}$ and the UK. ${ }^{2}$ Droeze and Jonsson ${ }^{30}$ have described the effect of introducing ergonomic interventions as a means of reducing musculoskeletal disorders (MSD) among dentists in the Netherlands, finding that the implementation of recommendations effected a reduction in MSD. However, it was concluded that, even in a highly motivated group, the implementation of recommendations will only be partly successful.

The response rate to the questionnaire in this study, especially in view of its length, may be considered satisfactory at 90\% of those retirees who agreed to take part and $50 \%$ of those who were considered suitable to take part. The response rate may also be considered to indicate an interest in the subject, a view reinforced by the fact that a number of respondents wrote letters or made telephone calls complimenting the researchers on examining this subject. The views of the retirees who declined to participate are not known. It is possible that non-respondents, compared to respondents, were enjoying life and did not wish to re-open old feelings related to their retirement, or, alternatively, that they were unhappy and/or depressed and did not wish to take part in the research. Nevertheless, the data contained in the responses may be considered to represent the first examination of the factors influencing IHR among a group of dentists and the effect of this on their lives.

The mean age of respondents at IHR was 51.5 years, having worked for a mean time of 27 years, with 90\% being general dental practitioners at the time of retirement, 77\% being employed full-time and $70 \%$ being practice owners. These retirements represent a considerable loss from the profession in the UK, with the loss of potential trainers and skilled practitioners, arguably at the top of their experience. In this respect, this paper provides evidence that there is a potential to retain many more of the highly skilled dental workforce who take IHR. This could be considered to indicate that at least some of the retirements were potentially unnecessary had there been occupational support or alternative work available. Furthermore, as $63 \%$ of respondents were able to keep working until their retirement, there must be a question as to whether this group actually needed to retire. These results therefore reinforce a view that steps should be taken to offer potential ill health retirees alternative or reduced employment within the profession in order to prevent their total retirement. However, few were offered the option of working part-time and, of those who were, 70\% took up this option. In this respect, it appears clear that working is good for well-being - 'good work is good for you. ${ }^{31}$

At the time of IHR, 83\% of respondents reported that they were under strain and $90 \%$ considered that their ill health was work-related. After retirement, more than half stated that they were more happy than usual and 63\% had positive views about their career. In addition, 63\% were able to continue working until the point of IHR but only $43 \%$ were positive about their method of employment. Given that a majority of the respondents' work was within the NHS regulations, it could be conjectured that it was not dentistry per se which resulted in the retirees' ill health, but that it was the system under which they worked that was the stressor.
The all or nothing attitude to retirement and working, in which ill health retirees are forced to retire fully without the option of taking part of their retirement package and working part-time, may result in the loss of a potentially effective part of the workforce and may be associated with increased dissatisfaction among ill health retirees and represents a poor use of the resources available. In this respect, 28\% and 34\% of respondents, respectively, stated that they would have liked to have been offered alternative or part-time employment, with just over a quarter of respondents stating that they investigated alternative work before retirement. It would therefore be reasonable to assume that, at retirement, a majority of respondents retained sufficient work ability to be able to continue to work in some capacity. Perhaps the lesson here for the National Pensions Agency, sickness insurance companies and organisations is that a proportion of ill health retirees would be content to remain in employment, albeit in a different or part-time, role. There should therefore be a greater focus on support and rehabilitation rather than the current 'stay or go' choices that many respondents reported. Indeed, it could be argued that the whole IHR process is not fit for purpose and, as a result, dentists are leaving the workplace unnecessarily. Furthermore, there is a systemic lack of employability advice and a lack of creativity in finding alternative work for dentists. There may also be perverse incentives within the insurance system by which dentists are put off seeking alternative careers because their insurance payments would be affected if they started earning another income.

Only a small proportion of respondents reported being offered advice around the time of their IHR. Of those who did report receiving advice, 71\% found it helpful, indicating a need for more advice to those who are suffering work-threatening illnesses. Regarding support, just over one third of respondents reported contacting an organisation for support before retirement, perhaps a surprisingly low figure. This might be considered to indicate that the retirees had come to terms with their premature retirement when it happened. Another surprisingly low figure is the proportion (28\%) of respondents who reported being offered occupational health advice 
before their retirement, with the majority of these being given advice on posture and coping with stress.

The present study examined the effects of IHR on a group of dentists who had retired because of illnesses which were not life-threatening. The results did not identify particular stressors within the dental surgery practising environment which may have contributed to premature retirement due to ill health in the group studied. Nevertheless, work appears to have played a large part in IHR of the respondents, given that only $11 \%$ of retirees stated that their IHR was not work related and at the time of IHR, 83\% of respondents reported being under strain. The lesson here is, perhaps, to identify those members of the profession who feel under work-related stress before it results in illness and IHR. Improved occupational support could therefore be considered an obvious first step. Who should provide that is another matter, but a partnership between the employers and the sickness insurance providers would seem to be the way ahead. This could improve workforce numbers and would result in cost savings as there would be no need to reimburse the ill health retirees and, moreover, the pension and sickness insurance providers would continue to receive their subscriptions.

Could there be a link between musculoskeletal problems and stress among dentists? The content and happy dentist may manage to work through the problems caused by musculoskeletal problems and receive treatment for stress; the unhappy dentist may not be prepared to do so. Since $90 \%$ of respondents reported that their retirement was work-related and over half reported that their health improved after retirement, there would appear to be a need to investigate this further.

The results of the present study have similarities to those from an earlier investigation of return to work of Scottish NHS staff and teachers who had taken IHR, ${ }^{17,18}$ despite the occupations being dissimilar. of 1,500 who were sent a questionnaire containing elements similar to that used in the present work, 282 teachers and 424 NHS staff completed the questionnaire. The mean age of retirement of NHS staff was 53.9 years and teachers 52.2 years. The most common cause of premature retirement was musculoskeletal disorders for
NHS staff and mental disorders for teachers, both of which were prevalent among dentists. Seventeen percent of NHS staff and $36 \%$ of teachers subsequently found employment (26\% of which was teachingrelated), a higher proportion than indicated by the results of the present study. This may suggest a different potential set of outcomes between teachers, and NHS staff and dentists. There is no bar to a return to teaching under the regulations of the Scottish Teachers' Superannuation Scheme, and, under the provisions of the scheme, the employment can be pensionable, whereas dentists who return to work under the NHS after receiving their pension following IHR may have adjustments to their pension.

The results of this research from Scotland ${ }^{19}$ also indicate other differences with the findings of the present study, principally in the use of occupational health services and rehabilitation. Ninety-six percent of NHS staff who took IHR had access to an occupational health advisor, while only $16 \%$ of teachers stated that an occupational health advisor was available to them. Forty-eight percent of NHS staff and $37 \%$ of teachers were offered rehabilitation to help with ill health before retirement. Why there is such a comparative dearth of occupational health advice available to or taken up by dentists is a matter for debate, but it could be considered that the example from these other professions must be followed by those who administer dentistry in the UK. Similarly, the fact that a proportion of dentists in the present study would have liked to return to work part-time is echoed by the results from the Scottish NHS workers and teachers. This may be considered to point to a need for consideration of a twotier pension scheme, in which the criteria for the lower tier includes permanency of ill health for the current job but for the upper tier any gainful employment.

In the population in the present study the factors that were associated with reemployment were age, having dependants, cause of IHR, health having improved and wanting to work again. Identifying health improvement and the desire to work again may not be possible at the point of IHR and these were excluded from the multiple logistic model. Although the combination of the three variables age, having dependents, and cause of IHR was predictive of re-employment status ( $\mathrm{p}=0.024)$, none of the variables individually were significant predictors of re-employment after IHR after adjusting for the others. Stepwise selection of variables was not used in the multiple logistic regression analysis because forward selection and backward elimination gave contradictory results. Forward selection resulted in only the age-group being included in the model, while backward elimination resulted in age-group being the only variable eliminated from the model. The model including all three predictors was used since this combination was predictive of re-employment status ( $p=0.024$ ) and there was no strong rationale for fitting a simpler model. Younger age, having dependants, and retiring because of a mental health problem could prove useful in identifying dentists who are more likely to respond to rehabilitation and job retention initiatives. Mental health problems, in particular anxiety and depression, tend to improve with treatment ${ }^{32,33}$ and many ill health retirees may have a manageable health condition where the outcome could be predicted to improve. In this respect, in the present study, $60 \%$ of respondents scored 'normal' for anxiety and 36\% 'mild' or 'moderate'. These retirees could therefore be considered to have a good chance of being able to return to the workplace, a similar finding to that in a study in IHR among teachers ${ }^{17}$. Early retirement need not therefore be the final outcome in such cases.

\section{CONCLUSIONS}

- The mean age at retirement of the premature retirees was 51.5 years, with a range of 31 to 62 years and the mean number of years for which respondents had been employed as a dentist was 27.4 years

- Sixty-three percent of respondents stated that they were able to keep working until their retirement

- Eleven percent of respondents considered that their IHR was not work related

- Regarding support before retirement, $37 \%$ of respondents contacted an organisation

- Fifty-four percent of respondents either obtained work after IHR or would like to work again

- A minority (28\%) of respondents were 
offered occupational health advice before their IHR, but this appeared to be of a reactive nature

- Thirty-four percent of respondents stated that they would have liked to have been offered part-time work

- Following IHR, 56\% of respondents considered that they were happier

- Regarding health post-retirement, 57\% of respondents reported that their health had improved since retirement

- Regarding the respondents' feeling about their career before IHR, 63\% of respondents presented positive feelings about their career, but, when asked about their feelings on their past method of employment, only 43\% were positive

- Thirty-eight percent of respondents considered that a self-help group would have been helpful

- Twenty-seven per cent of IHR dentists reported having found re-employment since their retirement. In univariate analyses, re-employment of dentists after IHR was significantly associated with age, having dependants, cause of IHR, health having improved and wanting to work again. Multiple logistic regression analyses showed that a combination of age, having dependents and cause of IHR was predictive of re-employment status $(\mathrm{p}=0.024)$.

Finally, these conclusions point to a need to reconsider the terms and conditions of IHR in the UK and there is a need to improve the provision of occupational health and rehabilitation and employability advice to dentists.
The authors wish to express their thanks to the following, without whose support this project could not have been undertaken: Wesleyan Medical Sickness and COPDEND (Committee of Postgraduate Dental Deaneries) for their financial support; the dentists who piloted the questionnaire and provided feedback; the dentists who agreed to take part and gave their time to complete the questionnaire and the interviews; and Professor Ruth Freeman, of the University of Dundee, for advice with the questionnaire.

1. Government's Actuary Department. Report by the Government Actuary on the National Health Service Pension Scheme 1989-1994. London: The Stationery Office, 1999.

2. Burke F J T, Main J R, Freeman R. The practice of dentistry: an assessment of reasons for premature retirement. Br Dent J 1997; 182: 250-254.

3. Howard J H, Cunningham D A, Rechnitzer P, Goode $\mathrm{R}$ C. Stress in the job and career of dentists. J Am Dent Assoc 1976; 93: 630-636.

4. Cooper C L, Watts J, Kelly M. Job satisfaction, mental health and job stressors among general dental practitioners in the UK. Br Dent J 1987; 162: 77-81.

5. Orner G, Mumma R D. Mortality study of dentists: final report, prepared for the National Institute for Occupational Safety and Health. Philadelphia: Temple University Health Sciences Center, School of Dentistry, 1976.

6. Balarajan R. Inequalities in health within the health sector. Br Med J 1989; 299: 822-825.

7. Gilmour J, Stewardson D A, Shugars D A, Burke F J T. An assessment of career satisfaction among a group of general dental practitioners in Staffordshire. Br Dent J 2005; 198: 701-704.

8. Blinkhorn A S. Stress and the dental team: a qualitative investigation of the causes of stress in general dental practice. Dent Update 1992; 19: 385-387.

9. Osborne $D$, Croucher $R$. Levels of burnout in general dental practitioners in the south-east of England. Br Dent J 1994; 177: 372-377.

10. Whitehead M. The health divide. In Inequalities in health. London: Penguin Books, 1988.

11. Scully C, Cawson R A, Griffiths M. Occupational hazards to dental staff. London: British Dental Association, 1990.

12. Te Brake H, Bloemendal E, Hoogstraten J. Gender differences in burnout among Dutch dentists. Community Dent Oral Epidemiol 2003; 31: 321-327.

13. Shugars $D$, Miller $D$, Willans $D$, Fishburne $C$, Strickland D. Musculoskeletal pain among general dentists. Gen Dent 1987; 35: 272-275.

14. Finsen $L$, Christensen $H$, Bakke M. Musculoskeletal disorders among dentists and variation in dental work. Appl Ergon 1998; 29: 119-125.

15. Lake J. Musculoskeletal dysfunction associated with the practice of dentistry - proposed mechanisms and management: literature review. Univ Tor Dent $J$ 1995; 9: 7,9-11.

16. Department of Health. Report of the Primary Care
Dental Workforce Review. London: Department of Health, 2004.

17. Brown J, Gilmour W H, Macdonald E B. III health retirement in Scottish teachers: process, outcomes and re-employment. Int Arch Occup Environ Health 2006; 79: 433-440.

18. Brown J, Reetoo N K, Murray K J, Thom W, Macdonald E B. The involvement of occupational health services before ill health retirement in NHS staff in Scotland and predictors of re-employmnent. Occup Med 2005; 55: 357-363.

19. Brown J, Gilmour W H, MacDonald E B. Return to work after ill-health retirement in Scottish NHS staff and teachers. Occup Med 2006; 56: 480-484.

20. Ilmarinen J, Rantanen J. Promotion of work ability during aging. Am J Ind Med 1999; 38: 21-23.

21. Crawford J R, Henry J D, Crombie C, Taylor E P. Normative data for the HADS from a large nonclinical sample. Br J Clin Psychol 2001; 40: 429-434

22. Moore R, Brodsgaard I. Dentists' perceived stress and its relation to perceptions about anxious patients. Community Dent Oral Epidemiol 2001; 29: 73-80.

23. Rada R E, Johnson-Leong C. Stress, burnout and depression among dentists. J Am Dent Assoc 2004; 135: 788-794.

24. Al-Khatib I A, Ishtayeh $M$, Barghouty $H$, Akkawi B. Dentists' perceptions of occupational hazards and preventive measures in East Jerusalem. East Mediterr Health J 2006; 12: 153-160.

25. Leggat P A, Chowanadisal S, Kewdjarune U, Kukiattrakoon B, Yapong B. Health of dentists in southern Thailand. Int Dent J 2001; 51: 348-352.

26. Gorter R C, Albrecht G, Hoogstraten J, Eijkman M A. Work place characteristics, work stress and burnout among Dutch dentists. Eur J Oral Sci 1998; 106: 999-1005.

27. Lindfors $P$, von Thiele $U$, Lundberg U. Work characteristics and upper extremity disorders in female dental health workers. J Occup Health 2006; 48: 192-197.

28. Sxzymaska J. Disorders of the musculoskeletal system among dentists from the aspect of ergonomics and prophylaxis. Ann Agric Environ Med 2002; 9: 169-172.

29. Lalumandler J A, McPhee S D, Parrott C B, Vendemia M. Musculoskeletal pain: prevalence, prevention and differences among dental office personnel. Gen Dent 2001; 49: 160-166.

30. Droeze E H, Jonsson H. Evaluation of ergonomic interventions to reduce musculoskeletal disorders of dentists in The Netherlands. Work 2005; 25: $211-220$.

31. Waddell G, Burton A K. Is work good for your health and well-being? London: The Stationery Office, 2006.

32. Bakish D. New standard of depression treatment: remission and full recovery. J Clin Psychiatry 2004; 62: 5-9.

33. Whitty P, Gilbody S. NICE, but will they help people with depression? The new National Institute for Clinical Excellence depression guidelines. $\mathrm{Br} J$ Psychiatry 2005; 186: 177-178. 